\title{
A COMPARISON OF CLOUDLESS SKY ERYTHEMAL ULTRAVIOLET RADIATION AT TWO SITES IN SOUTHWEST SWEDEN
}

\author{
MANUEL NUNEZ* and DELIANG CHEN \\ Earth Sciences Centre, University of Göteborg, Göteborg, Sweden
}

Received 30 May 1997

Revised 21 December 1997

Accepted 12 January 1998

\begin{abstract}
This case study examines the variability of ultraviolet erythemal radiation at two different but nearby locations in southwest Sweden. Data from two identical radiometers were analysed. One instrument sampled the urbanised environment of Göteborg (latitude: $57.70^{\circ} \mathrm{N}$, longitude: $12.00^{\circ} \mathrm{E}$ ), while the second one sampled a rural site, Koster Island (latitude: $58.83^{\circ} \mathrm{N}$; longitude: $11.00^{\circ} \mathrm{E}$ ), some $143 \mathrm{~km}$ to the north. Both radiometers were intercompared during the field season, and one radiometer had its calibration traced to a WMO/STUK intercomparison performed in 1995. Only cloudless data for the period 1 April 1996-30 September 1996 are examined in this study. Higher depletion was reported at Koster Island for the 4 days which were simultaneously cloudless at both sites. A cloudless model developed by Green et al. (Green, A.E.S., Cross, K.R. and Smith, L.A. 1980. Photochem. Photobiol., 31, 59-65.) was used to determine daily measured/model ratios for both sites. However there is some uncertainty in these ratios due to the spatial variability in total column ozone. Examining seasonal trends, much scatter is reported at both sites, although after day 226 (13 August 1996), distinctly lower ratios were reported at Koster Island. By examining pyranometer and relative humidity data at both sites, it is argued that coastal haze at Koster Island may explain the higher depletion there. (C) 1998 Royal Meteorological Society.
\end{abstract}

KEY WORDS: ultraviolet radiation; variability; southwest Sweden

\section{INTRODUCTION}

The well-documented process of global ozone depletion has encouraged programmes designed to measure the climatology and trends of surface ultraviolet radiation (Scotto et al., 1988; Seckmeyer and McKenzie, 1992; Justus and Murphey, 1994). Most measurement programmes consider analysis of point data, where the measured ultraviolet radiation may be related to changes in atmospheric opacity from the overlying atmosphere. However, few studies have examined the variability in the regional radiation field resulting from changes in atmospheric constituents, and yet knowledge of this variability is important if measurement programmes are to be set into context.

A variety of atmospheric depletion agents may act to produce localised changes in surface UV irradiance. Both theoretical (Nack and Green, 1974; Kylling, 1995) and experimental (Bais et al., 1993; Blumthaler et al., 1996; Nemeth et al., 1996) studies confirm the important depletion role that clouds play on surface ultraviolet radiation. Some initial papers encourage the prospects for using satellite-derived cloud data to resolve the regional field of UV-B radiation (Lubin et al., 1994; Nunez et al., 1997).

Stratospheric ozone is an important depletion agent which may vary at a regional scale. Total column ozone has been mapped globally using the TOMS instrument of NIMBUS-7 and METEOR-3. However, regional effects in surface UV irradiance may be missed by the coarse spatial resolution of the system.

\footnotetext{
* Correspondance to: Department of Geography and Environmental Studies, University of Tasmania, GPO Box 252C, Hobart, Tasmania 7001, Australia. Tel.: + 613 62262466; fax: +613 62262989; e-mail: nunez@utas.edu.au

Contract grant sponsor: Swedish Radiation Protection Institute.
}

CCC 0899-8418/98/080915-16\$17.50

(C) 1998 Royal Meteorological Society 
More local measurements are available from surface-based Brewer and Dobson spectrophotometers, but these are spatially limited.

Tropospheric aerosols may also undergo substantial changes at the regional scale. Liu et al. (1991) modelled a drop in UV-B irradiance levels of between 5 and 18\% in non-urban regions of industrialised countries since industrialisation began. Measurements by Zerefos et al. (1995) in various cities of Greece show a marked difference in monthly average and cloudless UV-B irradiance, with Athens reporting the lowest levels. Nemeth et al. (1996) working in Budapest, show a variability of broadband optical depths which were related to measured UV-B levels.

The objectives of this study are to examine the variability of erythemal UV radiation from two identical radiometers deployed at two different locations along the coast in southwest Sweden. One radiometer sampled in an urban environment close to the city centre of Göteborg; the second one sampled in a rural site some $200 \mathrm{~km}$ to the north. Results of this case study are useful in that they illustrate the variability that may be expected at the regional scale and the associated errors involved in taking a single point sample of irradiance in a region. Only cloudless data are examined in this study.

This study specifically examined if aerosols from urban sources produce significantly higher depletion inside urban areas, or if photochemical transformation and other non-local effects are sufficient to produce a more complex depletion pattern. In this initial study only two instruments are examined and some recommendations are made for future experiments.

\section{SITE CHARACTERISTICS AND DATA ACQUISITION}

Göteborg (Figure 1) is Sweden's second largest city with 440000 inhabitants, and is characterised by several industries dealing with car manufacture and communications. It is located in southwest Sweden with a climate that may be described as temperate maritime. The warmest month during 1996 was August, with mean maximum and mean minimum air temperatures of $24^{\circ} \mathrm{C}$ and $13^{\circ} \mathrm{C}$, respectively, reported at Säve Airport near Göteborg. The coldest month was February with mean maximum and mean minimum air temperatures of $-1^{\circ} \mathrm{C}$ and $-7^{\circ} \mathrm{C}$, respectively. Westerly systems feature prominently in the climate of the region, and in spring, summer and autumn, sea breezes are also important (Gustavsson et al., 1995).

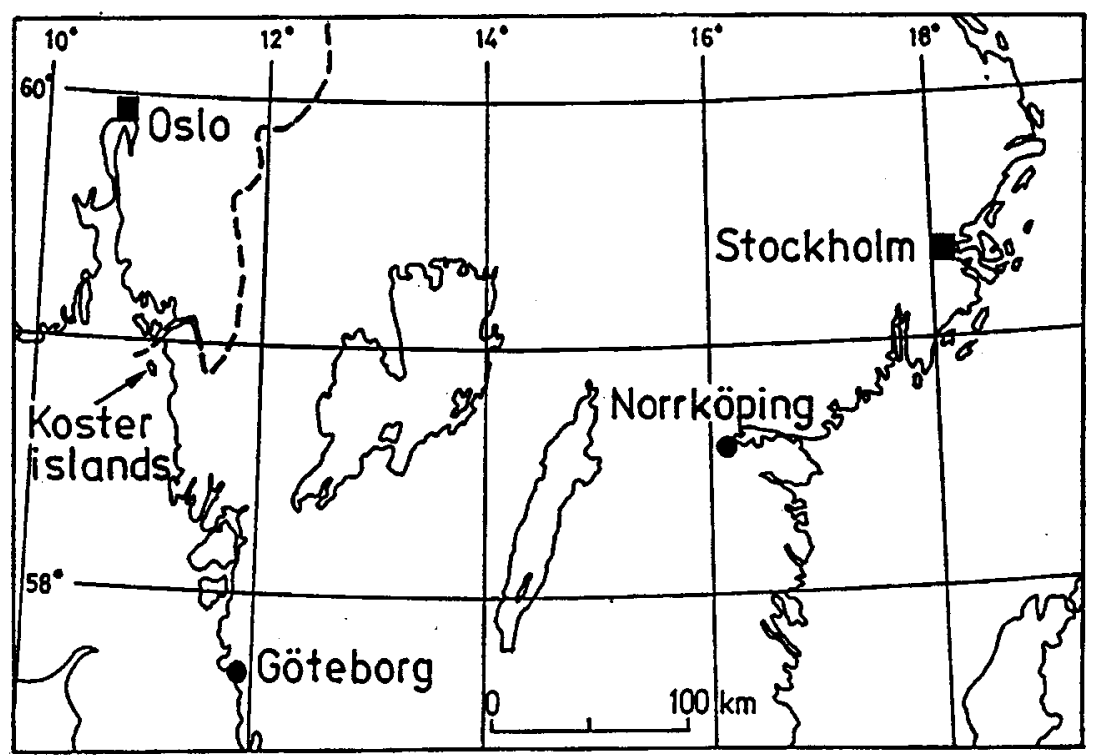

Figure 1. Regional map for the study area showing the two experimental sites, Göteborg and Koster Island. Total column data were obtained from Nörrkoping and Oslo 
Two identical instruments, a UV Biometer model 501 were used in the comparison. The instrument is a further development of the Robertson-Berger meter which essentially measures the UV-B irradiance as modulated by the standard erythemal action spectrum defined by the Comission International d'Eclarage (1987) (CIE). Ultraviolet radiation is transmitted through a quartz dome and glass filter which block longer wavelength solar radiation. The ultraviolet radiation sensitises a phosphor layer which emits visible light and is subsequently detected by a GaAsP diode. The current produced by the diode is changed into a voltage and amplified. The spectral responsivity of the instrument approximates the CIE action spectrum, so that the instrument output is linear when calibrated against measured spectral irradiance convolved with the CIE curve (Nunez et al., 1997). The instrument also features a temperature-stabilised detector and an improved cosine response curve (Solar Light 1991; Jokela et al., 1993).

The instrument output may then be related to the ambient and erythemal irradiance using:

$$
E_{\lambda}=C S=\int_{290 \mathrm{~nm}}^{400 \mathrm{~nm}} G_{\lambda} F_{\lambda} d_{\lambda}
$$

where $E_{\lambda}$ is the erythemal irradiance $\left(\mathrm{mW} \mathrm{m}^{-2}\right), C$ is the calibration constant of the instrument, $S$ (mW $\left.\mathrm{m}^{-2} \mathrm{mV}^{-1}\right), S$ is the instrument signal $(\mathrm{mV}), G_{\lambda}$ is the global spectral irradiance incident at the surface $\left(\mathrm{mW} \mathrm{m}^{-2} \mathrm{~nm}^{-1}\right.$ ), and $F_{\lambda}$ is the CIE erythemal action spectrum. Thus the spectral solar irradiance $G_{\lambda}$ is convolved by the erythemal curve $F_{\lambda}$, this last quantity reaching a maximum value of ' 1 ' at $297 \mathrm{~nm}$ and decreasing to very low values for wavelengths larger than $325 \mathrm{~nm}$.

One instrument was deployed on the roof of the Earth Sciences Building, University of Göteborg, located approximately $2 \mathrm{~km}$ south of the city centre of Göteborg (latitude: $57.70^{\circ} \mathrm{N}$; longitude: $12.00^{\circ} \mathrm{E}$ ). It was installed on 21 February 1996 and was running continuously for the duration of this study with the exception of two periods related to instrument comparison and calibration. Millivolt output from the instrument was fed into a Campbell CR 10 data logger at a rate of one data frame every $10 \mathrm{~s}$, integrated every $10 \mathrm{~min}$ and stored on hard disk.

The second instrument measured erythemal irradiance at South Koster Island, located in the Skagerrak, close to the Norwegian border, some $10 \mathrm{~km}$ west of the town of Stromstad (latitude: $58.83^{\circ} \mathrm{N}$; longitude: $11.00^{\circ} \mathrm{E}$ ). The site is rural and is located $143 \mathrm{~km} \mathrm{NNW}$ of Göteborg and $120 \mathrm{~km} \mathrm{SSE}$ of Oslo. Therefore concentrations of anthropogenic aerosols of local origin are minimal. Continuous measurements have been conducted since 2 June 1994 at the Research Station Kilesandsgarden, Koster Health Foundation, Göteborg University. The radiometer was mounted on the upper wooden deck of the station from its initial deployment until June 1996, after which it was moved to a platform above the roof with a higher sky view factor. The only significant obstruction to the radiometer in the first position was a building wall, although calculations showed that it blocked only $1.2 \%$ of the effective view of the radiometer. The homogeneity of the two locations were further verified by spot measurements of UVB irradiance. Results failed to show a detectable difference between the two sites. Signals from the radiometer were also acquired by a Campbell CR10, integrated hourly and stored on hard disk using an IBM PC. The signals were integrated every half hour after 28 May 1996. Two field tests were performed on the instruments. The Göteborg instrument was intercompared with another Solar Light 501 Biometer from the Swedish Meteorological and Hydrological Institute (SMHI) which had a calibration traced to a WMO/STUK 1995 intercomparison (Josefsson, 1996, personal communication). Comparison of the two instruments (SMHI and Göteborg) at Nörrkoping during a three day period in June 1996 gave a cosine-corrected calibration factor (SMHI/Göteborg) of 1.15. All data from the Göteborg instrument were adjusted by this constant factor.

The second comparison was conducted at South Koster Island on 7 and 8 May 1996, with the Göteborg and Koster instrument sampling the same ambient irradiance. Figure 2A shows the relative output of the two instruments when averaged over a 10 min period. A linear regression between the two instruments gave:

$$
\begin{aligned}
& Y=-0.402+1.021 X \quad(\mathrm{mv}) \\
& r=0.999
\end{aligned}
$$




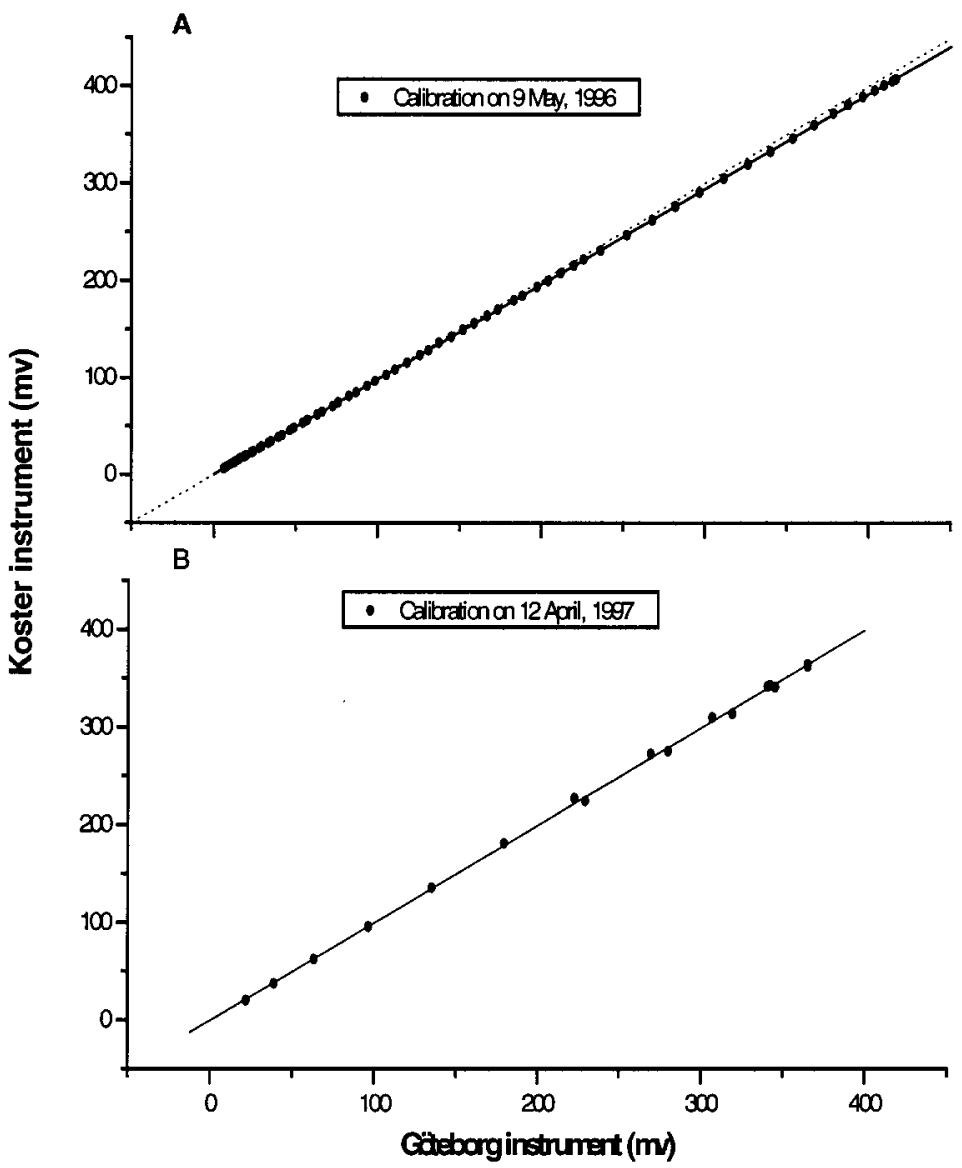

Figure 2. Comparison of data from two UV 501 Biometers. It was conducted at Koster Island on 7 May 1996-8 May 1996, with the Göteborg and Koster instrument sampling the same erythemal irradiance

where $X$ and $Y$ are the mv output of the Koster Island and Göteborg instrument respectively. A second field intercomparison was performed at Koster Island after the field season (12 April 1997). Regression results of $10 \mathrm{~min}$ average comparisons were very similar to the first intercomparison (Figure 2(b)):

$$
\begin{aligned}
& Y=-0.417+1.000 X \quad(\mathrm{mv}) \\
& r=0.999
\end{aligned}
$$

Therefore both the absolute and relative calibration of the two instruments were assumed stable during the measurement period.

The final calibration factor used for the two instruments was:

$$
\text { Göteborg: } \quad \mathrm{mv} \times 0.26818=\mathrm{mWm}^{-2}
$$

Koster Island: $(\mathrm{mv} \times 1.0123-0.402) \times 0.26818=\mathrm{mWm}^{-2}$

Data from the two instruments were acquired for a time period encompassing 1 April 1996-30 September 1996. The study was restricted to the above dates for several reasons. Firstly it was considered important to examine the six-month period when radiation levels are high and are biologically important. In addition, cosine errors become large in wintertime when both the instrument signals and solar elevations are low.

Additional data sources included daily total column ozone from Brewer instruments at the WMO stations in Nörrkoping, Sweden (latitude: $58.58^{\circ} \mathrm{N}$; longitude: $16.15^{\circ} \mathrm{E}$ ) and Oslo, Norway (latitude: 
Table I. Data used in this study (1 April-30 September 1996)

\begin{tabular}{lll}
\hline & Göteborg & Koster Island \\
\hline UVB erythemal irradiance & Yes & Yes \\
Broadband solar irradiance & Yes & Yes \\
Hourly bright sunshine duration & Yes & Yes \\
Three hourly air temperature & Yes & Yes \\
Three hourly relative humidity & Yes & Yes \\
Three hourly wind direction & - & Yes \\
Three hourly total cloud cover & N.A. & Yes \\
Three hourly visibilitly & N.A. & Yes \\
\hline
\end{tabular}

$59.95^{\circ} \mathrm{N}$; longitude: $10.72^{\circ} \mathrm{E}$ ). Hourly sunshine duration, three hourly visibility, cloud type, cloud cover, wind speed and wind direction were also obtained for North Koster Island (latitude: $58.88^{\circ} \mathrm{N}$; longitude: $11.00^{\circ} \mathrm{E}$ ). Hourly sunshine duration was obtained for central Göteborg, but cloud data and visibility were not, as these variables were not recorded there during 1996. Broadband solar radiation data were also examined for both Göteborg and Koster Island. Table I summarises data that was processed in this study.

\section{ANALYSIS OF RESULTS}

\subsection{Selection of cloudless data}

Cloud depletion must be minimised to examine the effect of aerosol at both sites. Ideally, cloudless days should be selected from the available radiation data. However there occured problems in that cloud data is collected at North Koster Island but not at central Göteborg. Both stations record hourly bright sunshine fraction. Therefore hourly sunshine duration was used to approximate cloudless conditions at both sites. Absence of clouds will translate as a sunshine duration of one only for near-cloudless conditions.

A cloudless day was taken as one in which there was not more than three occasions between 06:00 and 18:00 $\mathrm{h}$ local time with sunshine fraction less than one. A total of 30 days were available at North Koster Island which met this sunshine duration criteria. This data was then compared with the daily average of three-hourly cloud cover (06:00, 09:00, 12:00, 15:00 and 18:00 h GMT) for the same days also at North Koster Island.

Forty percent of the days had a mean cloud cover of 1 octa or less. Seventy percent had a mean cloud cover of 2 octas or less, and only one day exceeded 3 octas (3.2 octas on the 10 June 1996). Although a sunshine fraction of 1 will allow some cloud cover, we consider that sunshine duration is a useful and practical method to select radiation days that are not dominated by cloud cover.

In the remainder of this paper, a cloudless day will be interpreted as satisfying the sunshine criteria. There were a total of 17 and 27 cloudless days at Göteborg and Koster Island, respectively. All these days had concurrent radiation data.

\subsection{Comparison of measured irradiance data}

Figure 3 shows daily irradiance data for both Göteborg and Koster for all days of the study period. A seasonal cycle is clearly seen which is superimposed on the daily scatter. Also shown is the daily difference between the two sites. As may be noticed, there is much daily scatter in this difference data, and this is

mostly due to cloud cover. Table II presents monthly statistics for daily irradiance. Mean bias difference gives higher irradiance at Göteborg for five out of the six months. Furthermore, values become increasingly higher at Göteborg in the last two months of the study, August and September, but the S.D. of the daily difference decreases. 
Table II. Statistics for all daily irradiance data that is concurrent

\begin{tabular}{llllll}
\hline Month & $\begin{array}{l}\text { Mean daily irradiance } \\
\text { for Koster }\left(K_{\mathrm{k}}\right)(\mathrm{kJ} \\
\left.\mathrm{m}^{-2} \text { day }^{-1}\right)\end{array}$ & $\begin{array}{l}\text { Mean daily irradiance } \\
\text { data for Goteborg } \\
\left(K_{\mathrm{g}}\right)\left(\mathrm{kJ} \mathrm{m}^{-2} \text { day }\right.\end{array}$
\end{tabular}

Figure 4 presents a diurnal cycle for four days in the study which were cloudless and irradiance data were available at both locations. On 14 April the measured data for the two stations were very similar and a daily difference of $-0.02 \mathrm{~kJ} \mathrm{~m}^{-2}$ day $^{-1}$ was obtained between the irradiance at Koster $\left(2.10 \mathrm{~kJ} \mathrm{~m}^{-2}\right.$ day $\left.^{-1}\right)$ minus the irradiance at Göteborg $\left(2.12 \mathrm{~kJ} \mathrm{~m}^{-2} \mathrm{day}^{-1}\right)$. Predominant winds at North Koster Island were 5-6 $\mathrm{m} \mathrm{s}^{-1}$ and from NNE between 06:00 and 18:00 h. At later dates the irradiance difference increases, with $-0.20 \mathrm{~kJ} \mathrm{~m}^{-2}$ day $^{-1}$ being obtained on 12 May 1996 (Koster at $2.70 \mathrm{~kJ} \mathrm{~m}^{-2}$ day $^{-1}$ - Göteborg $2.90 \mathrm{~kJ} \mathrm{~m}^{-2}$ day $^{-1}$ ), -0.64 on 19 August 1996 (Koster at $2.28 \mathrm{~kJ} \mathrm{~m}^{-2}$ day $^{-1}$ Göteborg $2.92 \mathrm{~kJ} \mathrm{~m}^{-2}$ day $^{-1}$ ) and $-0.72 \mathrm{~kJ} \mathrm{~m}^{-2}$ day $^{-1}$ on 20 August 1996 (Koster $2.14 \mathrm{~kJ} \mathrm{~m}^{-2}$ day $^{-1}$ minus Göteborg $2.86 \mathrm{~kJ} \mathrm{~m}^{-2} \mathrm{day}^{-1}$ ). Wind speeds were light and at $5 \mathrm{~m} \mathrm{~s}^{-1}$ or less and all had an easterly component (SE on 12 May, E on 19 August and SE on 20 August 1996.).

Synoptic pressure charts for these four days also reveal some differences. On 14 April there was an extensive zone of high pressure encompassing western Scandinavia to Greenland. Regional winds would be close to zero in the study region. On 12 May the regional flow was NE and was steered by a low pressure system centred in the Adriatic sea. The air mass source is from land but does not traverse a highly urbanised region. However, on 19 and 20 August there was a blocking high situation in eastern Europe which was associated with the transport of an air mass from central Europe to southwestern Scandinavia. This particular weather system appeared prominently on the August charts, featuring on 11 days.

Both the monthly average and daily cloudless data suggest that Koster Island experienced increased UV radiation depletion as the summer season progressed. Unfortunately the number of simultaneous cloudless days are very few to arrive at any conclusions. Another possible approach is to refer cloudless irradiance data at each station to a clear sky model. The larger number of data at each station may then help define trends.

\subsection{Comparison with clear sky model}

The algorithms developed by Green et al. (1980) and discussed by Baker et al. (1980) were used in the analysis. This model estimates direct and diffuse spectral irradiances at $1 \mathrm{~nm}$ resolution as a function of solar zenith angle. Rayleigh scattering, ozone absorption and aerosol depletion are taken into account with user-defined inputs for solar zenith angle, total ozone load and aerosol optical depth. Diffuse radiation is solved empirically taking into account the multiple scattering calculations of Braslau and Dave (1973) and Dave and Halpern (1976).

Daily measured and model irradiance data were compared for both Göteborg and Koster Island. The approach followed is to observe daily irradiance ratios, $R_{\mathrm{uv}}$ (measured/model) for all cloudless data. The model uses a constant wavelength-independent value of 0.05 for the aerosol optical depth obtained for mean cloudless conditions by Baker et al. (1980). Additional inputs consisted of total column ozone obtained daily at Nörrkoping and Oslo, the two nearest stations which use Brewer instruments. Figure 5 presents the results.

There is a considerable amount of scatter in the ratio at Göteborg, but no evidence of a seasonal trend. For all 17 days, a mean ratio of 1.00 is obtained with the Nörrkoping ozone data. The S.D. of the data set is 0.058 . Use of the Oslo data set shows a slightly lower ratio (0.98) and a slightly higher S.D. (0.06). 

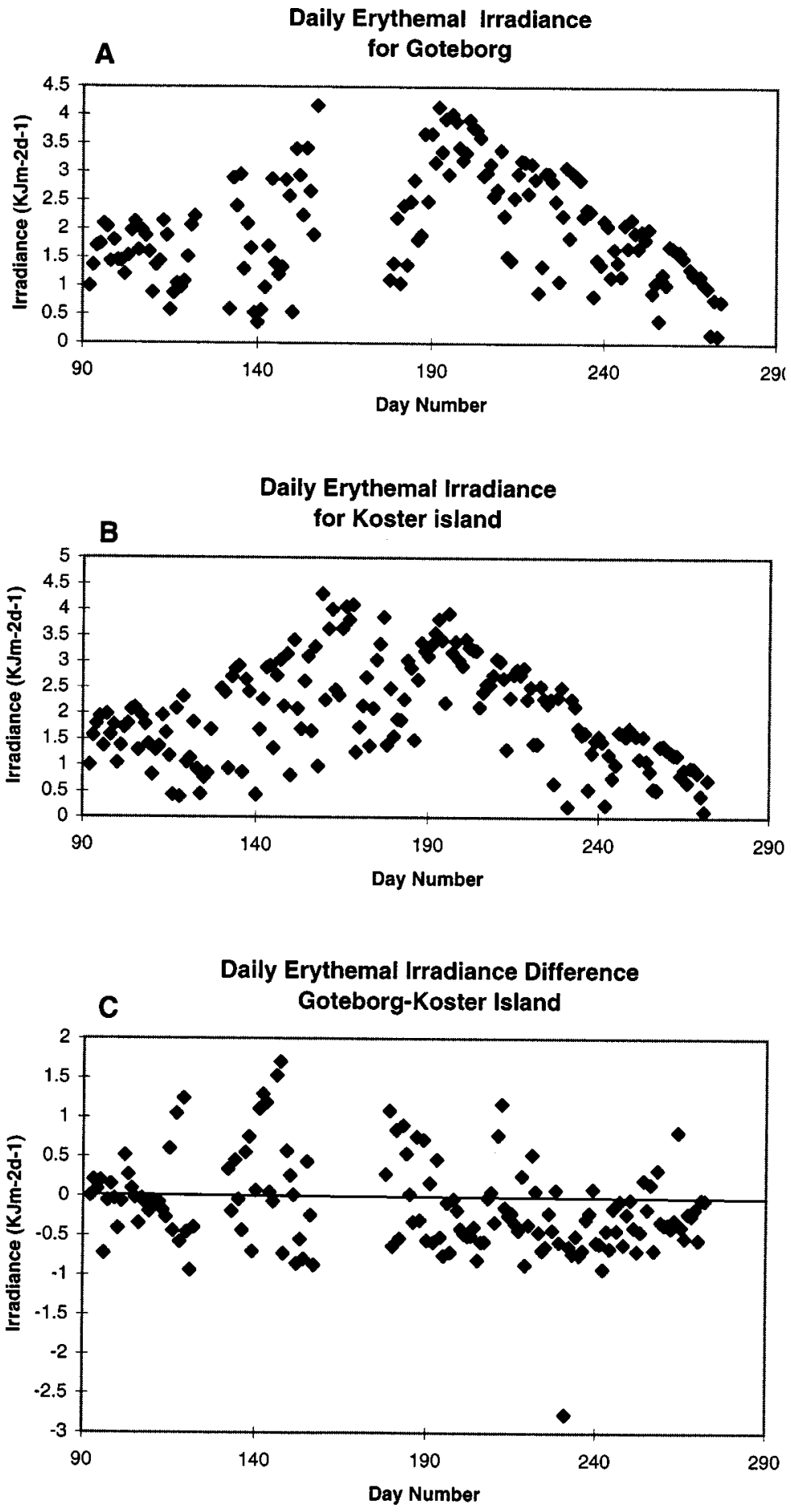

Figure 3. Seasonal distribution of daily erythemal irradiance for (a) Göteborg, (b) Koster Island and (c) is their daily difference. All data are in units of $\mathrm{kJ} \mathrm{m}^{-2}$ day $^{-1}$ 

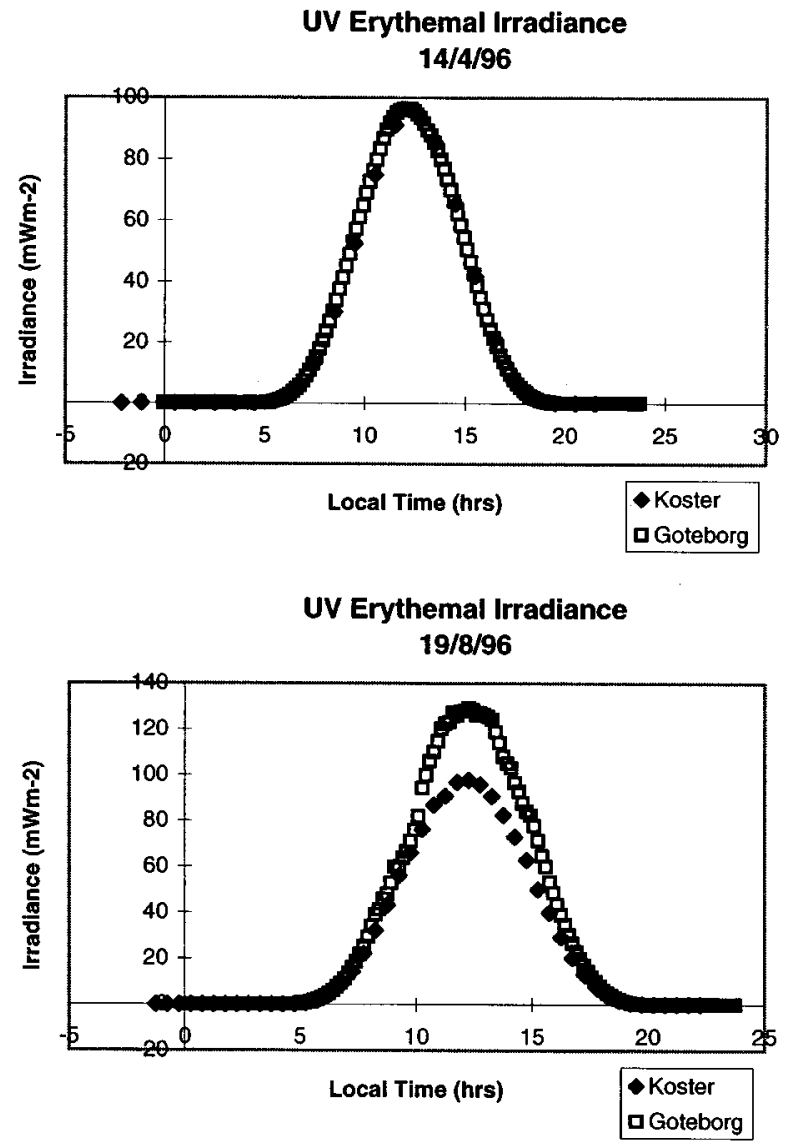

UV Erythemal Irradiance 12/5/96

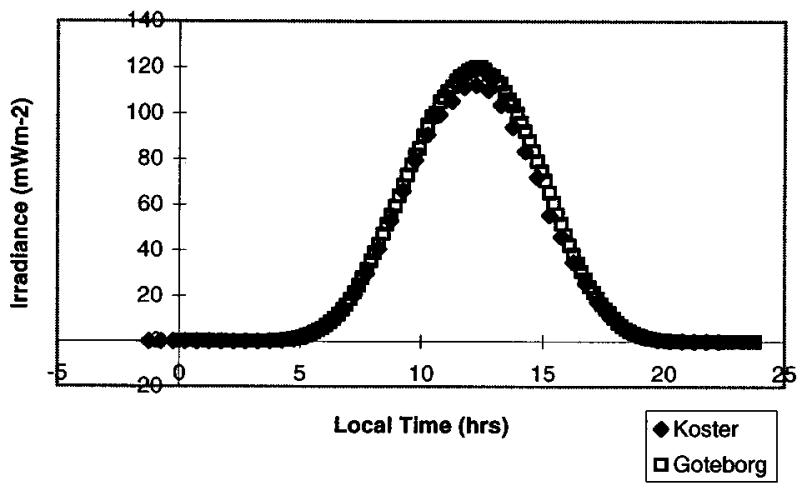

UV Erythemal Irradiance 20/8/96

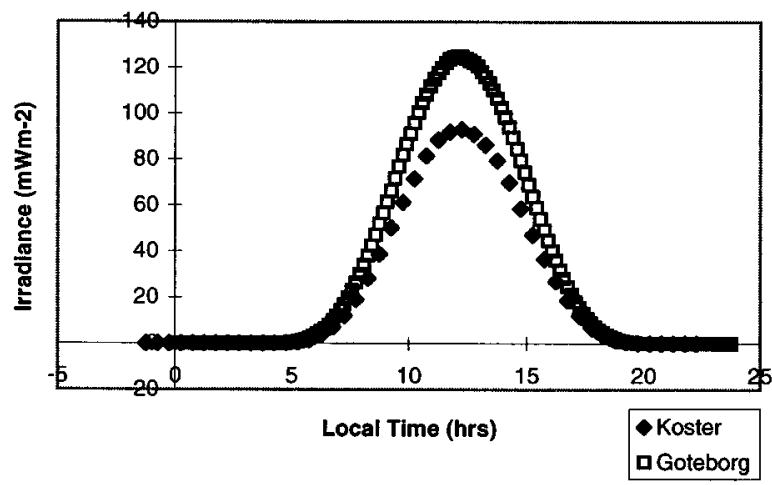

Figure 4. Diurnal distribution of erythemal irradiance for four days that were cloudless at both sites. All data are in units of $\mathrm{mW}$ $\mathrm{m}^{-2}$

Results for Koster Island appear different, although it must be emphasised that the two data sets are not concurrent. Examining the Nörrkoping data first, days 92-210 (1 April-28 July) exhibit scatter about the 1.0 ratio, but with no apparent trend. Mean ratios and S.D. are 1.0 and 0.10 respectively for this time period. However after day 226 mean ratios (days 226-261) are considerably lower at 0.82 .

The same features appear in the Oslo data, except that ratios are slightly lower (Table III). This is a result of the slightly lower daily ozone reported at Oslo, resulting in larger irradiances for model calculations. Daily average data was 312.1 Dobson units (DU) for Oslo and 317.1 DU for Nörrkoping. Values are also higher at Nörrkoping when averaged over all 27 cloudless days at Koster Island, 322.8 DU versus 310.7 DU. On individual days the ozone differences reported by the two stations may be quite large. For example, on day 249 (5 September) Oslo reported 262 D.U. but the reading at Nörrkoping was 305 D.U. Large differences persisted for the following day as well. Resultant model daily erythemal irradiances were 2.12 $\mathrm{kJ} \mathrm{m}^{-2}$ day $^{-1}$ using the Oslo data, but only $1.79 \mathrm{~kJ} \mathrm{~m}^{-2}$ day ${ }^{-1}$ using the Nörrkoping data. This considerably higher irradiance will translate into a lower irradiance ratio for the Oslo data (Figure 5).

\subsection{Broadband solar radiation analysis}

Broadband solar radiation depletion may be a useful indicator of the total turbidity of the atmosphere. For cloudless conditions, broadband radiation is reacting not only to aerosols, but to total column water vapour and carbon dioxide as well as other minor constituents of the atmosphere (Iqbal, 1983). Absorption by water vapour and other gases can be large in tropical atmospheres, but temperate mid-latitude locations 
will exhibit lower absorptivities and smaller day-to day variations (Nunez and Kalma, 1996). Therefore it was decided to examine broadband solar radiation as an index of turbidity to accompany the ultraviolet radiation measurements.

Pyranometer measurements were available at both sites. Data for central Göteborg was collected by SMHI using a Kipp and Zonen model CM-11. In Koster Island a Kipp and Zonen model CM-5 was

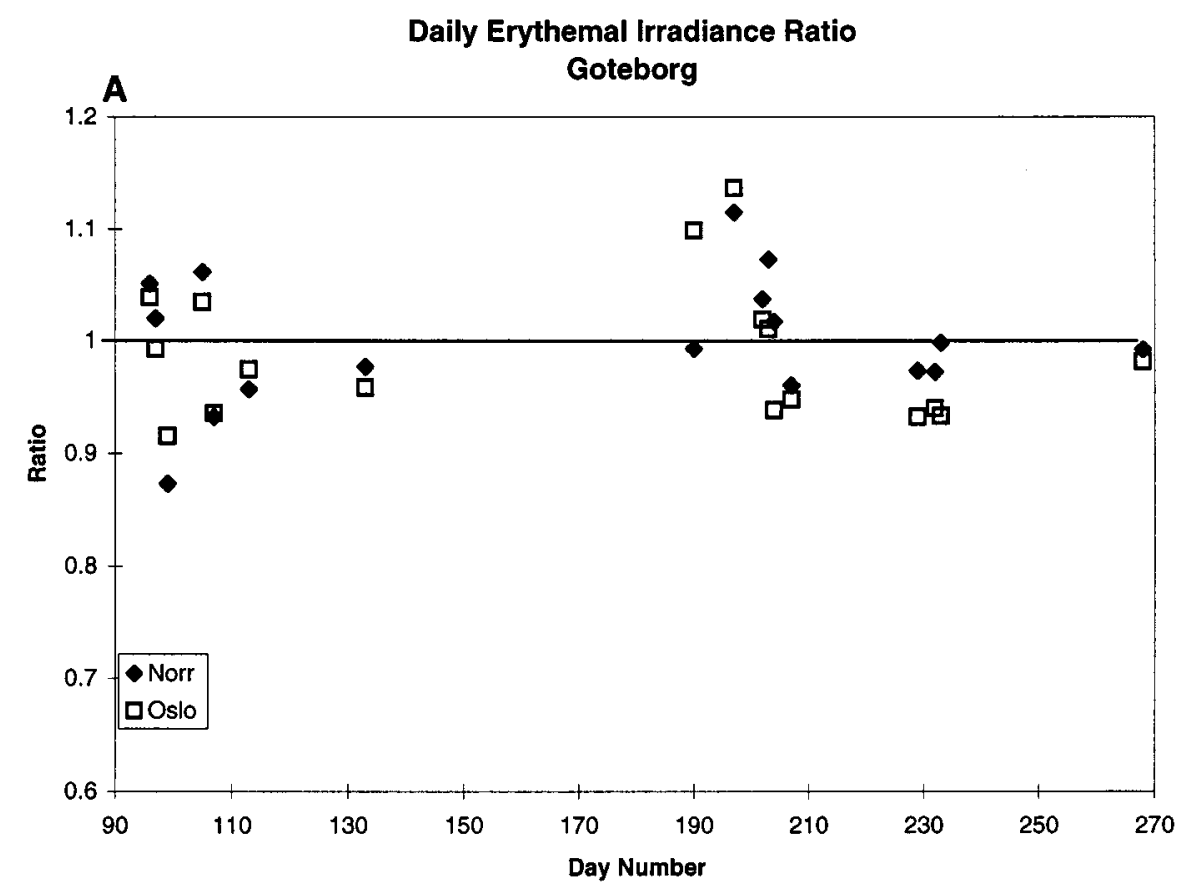

Daily Erythemal Irradiance Ratio

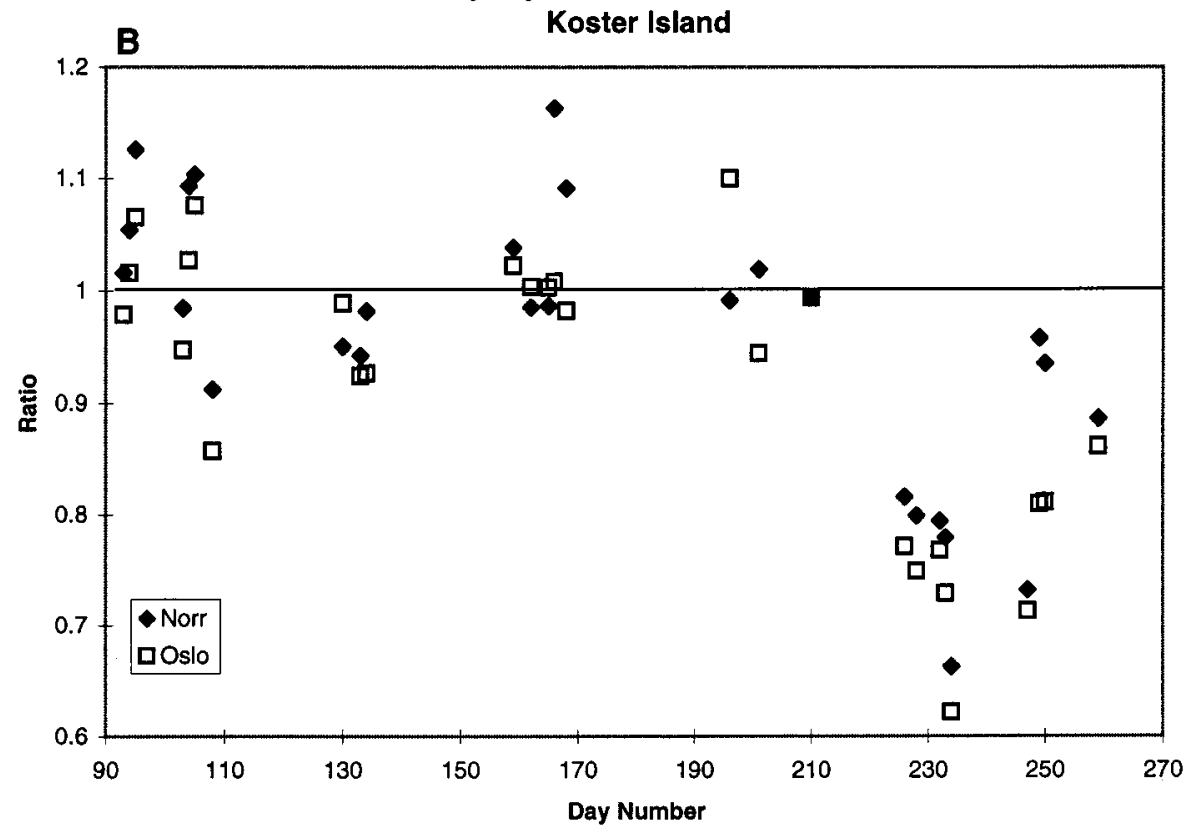

Figure 5. Ratio of measured to model daily erythemal irradiance for cloudless conditions (1 April 1996-30 September 1996). Black diamonds and squares refer to ozone data from Norrköping and Oslo respectively. (a) Seasonal trends in the ratio at Göteborg. (b) Seasonal trends in the ratio at Koster Island 
Table III. Statistics of measured/model ratios for cloudless days

\begin{tabular}{lllllll}
\hline & $\begin{array}{l}\text { Day 90-270 } \\
\text { Norrköping }\end{array}$ & $\begin{array}{l}\text { Day 90-270 } \\
\text { Oslo }\end{array}$ & $\begin{array}{l}\text { Day 90-210 } \\
\text { Norrköping }\end{array}$ & $\begin{array}{l}\text { Day 90-210 } \\
\text { Oslo }\end{array}$ & $\begin{array}{l}\text { Day 211-270 } \\
\text { Norrköping }\end{array}$ & $\begin{array}{l}\text { Day 211-270 } \\
\text { Oslo }\end{array}$ \\
\hline$R_{\mathrm{G}}$ & $1.00(17)$ & $0.99(17)$ & $1.00(13)$ & $0.98(13)$ & $0.98(4)$ & $095(4)$ \\
$R_{\mathrm{K}}$ & $0.96(27)$ & $0.91(27)$ & $1.02(18)$ & $0.82(18)$ & $0.82(9)$ & $0.76(9)$ \\
$R_{\mathrm{G}} / R_{\mathrm{K}}$ & 0.96 & 0.92 & 1.02 & 0.84 & 0.84 & 1.25 \\
S.D. $R_{\mathrm{G}}$ & 0.06 & 0.06 & 0.06 & 0.01 & 0.01 & 0.02 \\
S.D. $R_{\mathrm{K}}$ & 0.12 & 0.13 & 0.07 & 0.09 & 0.09 & 0.07 \\
\hline
\end{tabular}

$R_{G}$, mean daily ratios for Göteborg; $R_{\mathrm{K}}$, mean daily ratios for Koster Island; S.D. $R_{\mathrm{G}}$, S.D. of daily ratios for Göteborg; S.D. $R_{\mathrm{K}}$, S.D. of daily ratios for Koster Island.

The values in parenthesis refer to the number of data points

used. For each cloudless day the ratio of daily measured global radiation $(K)$ to the extra-terrestrial solar radiation $\left(K_{0}\right)$ was calculated, i.e.

$$
R_{\mathrm{gl}}=K / K_{0}
$$

Estimation of $K_{0}$ involved selecting the latitude of the site and estimating a daily broadband irradiance after correction for the radius vector of the sun (Iqbal, 1983). The ratio was calculated using cloudless days for 1996 at both Koster Island and Göteborg. For purposes of comparison, solar radiation data was also available for Koster Island for 1995 and 1994. Using the same cloudless day selection as listed above, $R_{\mathrm{gl}}$ was also calculated for Koster Island for 1995 and 1994. Figure 6 presents the results.

Figure 6(a) shows the ratio for Koster Island during 1994, 1995 and 1996. A polynomial fit to the data gives maximum ratios at days $160-170$, and a decreasing trend above and below this time period. Figure 6(b) shows the corresponding pattern for Göteborg. There is much scatter in the ratio and the number of data points are limited, however there is not much evidence of a seasonal trend.

A decrease in $R_{\mathrm{gl}}$ would indicate that there is some atmospheric depletion agent that is increasing in effectiveness as the season progresses. Atmospheric water vapour is an obvious agent as a warmer ocean would be increasingly more effective in evaporating into the atmospheric column. However no depletion in ultraviolet radiation would occur if the atmospheric turbidity were restricted only to water vapour.

Data for erythemal irradiance ratios $\left(R_{\mathrm{uv}}\right)$ were plotted against broadband solar transmission $\left(R_{\mathrm{gl}}\right)$ for both Göteborg and Koster Island. Values of $R_{\mathrm{uv}}$ were obtained by taking an average of the daily ozone at both Göteborg and Koster Island. The two data sets are not exactly analogous as $R_{\mathrm{gl}}$ refers to the transmission of broadband solar radiation through the entire atmosphere, and $R_{\mathrm{uv}}$ refers to a transmission after calculation for mean conditions at the earth's surface. Therefore $R_{\mathrm{uv}}$ should isolate the effects of aerosols in the atmospheric column, whilst $R_{\mathrm{gl}}$ samples the entire atmosphere. However the two variables should relate if the effect of water vapour absorption is conservative.

A regression analysis for the Göteborg and Koster Island data is presented in Equations 5(a) (Göteborg) and 5(b) (Koster Island), and Figure 7:

$$
\begin{aligned}
R_{\mathrm{uv}} & =1.3065-0.464 R_{\mathrm{g} 1} \quad \text { (Göteborg) } \\
r^{2} & =0.087 \\
\text { S.D. } & =0.052 \\
N & =17 \\
R_{\mathrm{uv}} & =-0.462+1.900 R_{\mathrm{g} 1 \quad \text { (Koster Island) }} \\
r^{2} & =0.46 \\
\text { S.D. } & =0.079 \\
N & =27
\end{aligned}
$$


There is no relationship for Göteborg, but the regression explains $46 \%$ of the variance in $R_{\mathrm{uv}}$ for the case of Koster Island. For a data set of 27 pairs there is a probability of less than 0.01 that the relationship is by chance. Therefore it appears that there is agreement in slightly less than half of the daily fluctuations

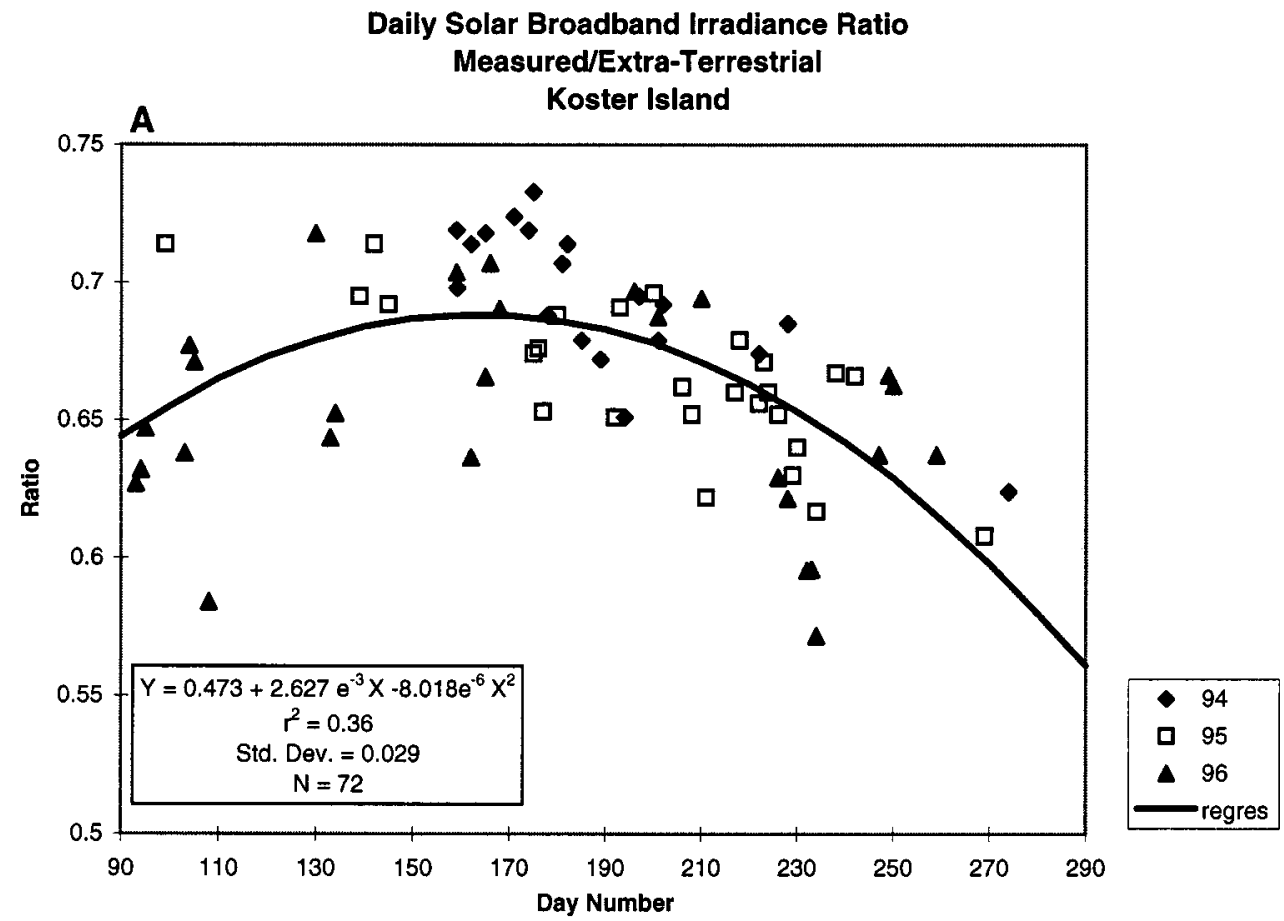

Daily Solar Broadband Irradiance

Measure/Extra-Terrestrial

B

Goteborg

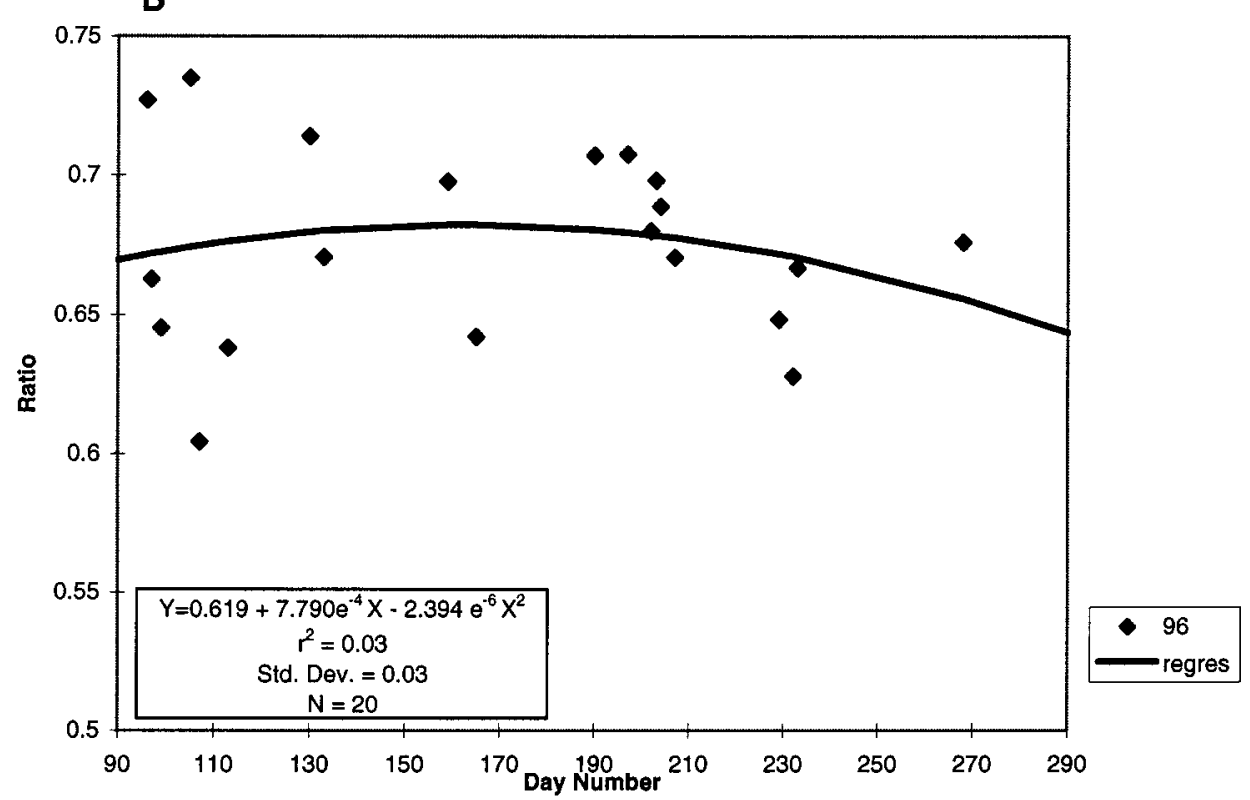

Figure 6. Ratio of daily measured to extra-terrestrial broadband solar irradiance for cloudless conditions. (a) Seasonal distribution for days in 1994, 1995 and 1996 at Koster Island. (b) Seasonal distribution for Göteborg in 1996 
Erythemal Irradiance Ratio

vs Broadband Solar Transmission

A

Goteborg
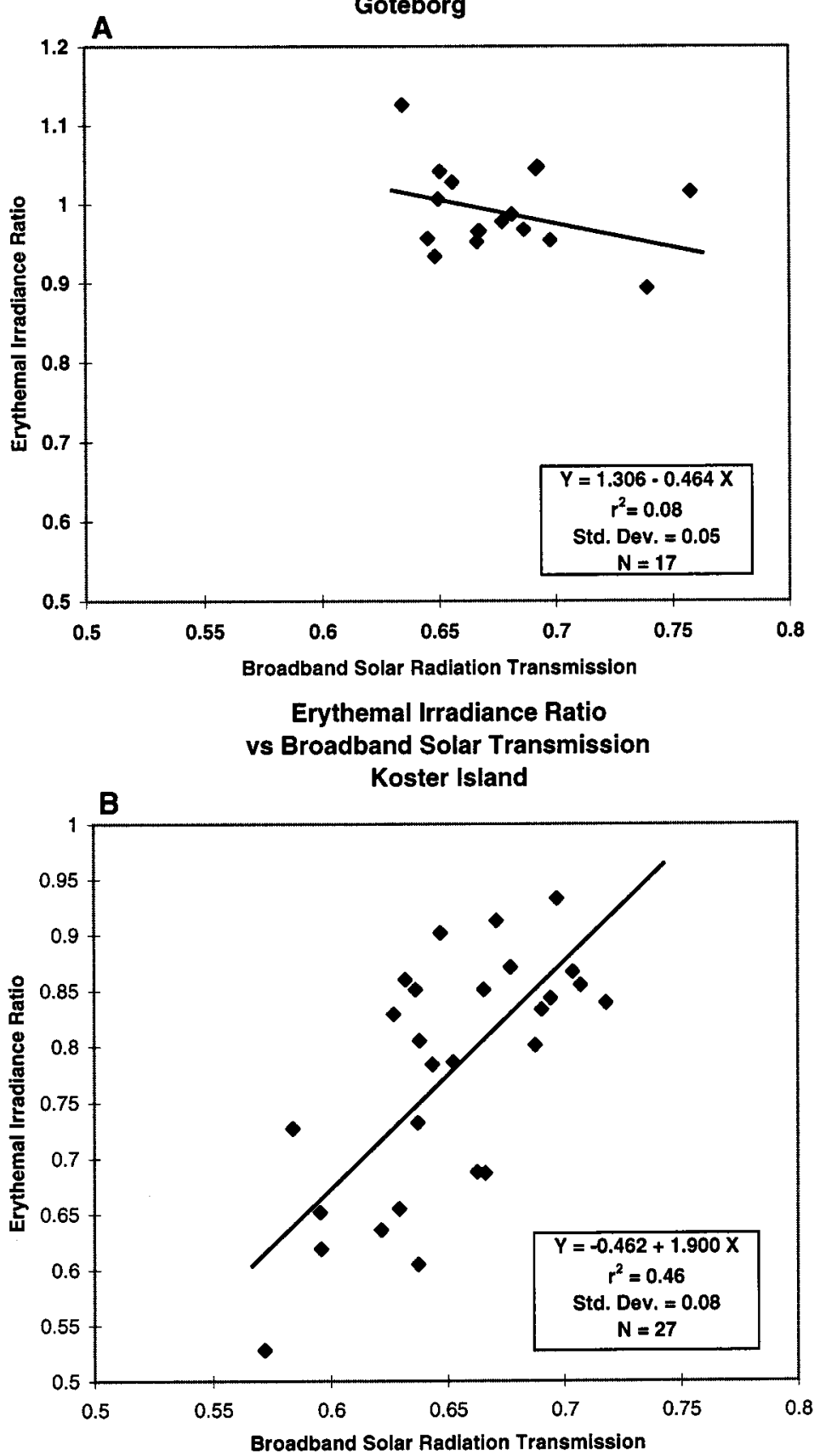

Figure 7. Erythemal irradiance ratios (measured/model) versus broadband solar radiation transmission (measured/extra-terrestrial) for (a) Göteborg and (b) Koster Island

in $R_{\mathrm{uv}}$ and $R_{\mathrm{gl}}$ at Koster Island. These results point to the important role of aerosols acting in both the broadband and UV erythemal bands.

Examination of the Göteborg results reveal a more restricted range of $R_{\mathrm{uv}}$ and $R_{\mathrm{gl}}$ values (Figure 7(a)), with $R_{\mathrm{gl}}$ ranging from 0.634 to 0.758 and $R_{\mathrm{uv}}$ ranging from 0.894 to 1.126 . In other words, the cloudless sky filter never allowed broadband transmissions or erythemal ratios that were as low as the data set 
represented by Equation 5(b) and Figure 7(a). As a result they are grouped at the high end of the scale with no trend or correlation.

\subsection{Relationship to wind direction and water vapour density}

Erythemal transmissions may be grouped together according to wind direction and water vapour density. Aerosols from different air mass sources may present quite different properties and therefore affect the erythemal transmission differently. Water vapour density at the earth's surface may be a convenient way of characterising the possible growth of water vapour droplets, which in turn will increase the aerosol optical depth of the air mass.

Three hourly wind speed and direction data for North Koster Island were examined for cloudless days encompassed in this study. Each day was characterised by the most frequent wind direction between 09:00 and 12:00 h GMT. Wind direction was further grouped into three categories. The first category encompassed all wind directions with a westerly component. The second category encompassed easterly winds. The third category encompassed days with no consistent wind direction.

Figure 8(a) presents the results of $R_{\mathrm{uv}}$ (also obtained using ozone averages from Oslo and Norrköping) versus water vapour density for different wind direction categories. With the limited data set, there is no particular wind direction that is associated with either high or low transmissivities. There is however a distinct trend showing that the transmissivities are related to surface water vapour density. The regression relationship is:

$$
\begin{aligned}
R_{\mathrm{uv}} & =1.1135-0.0255 D \quad(\text { Koster Island }) \\
r^{2} & =0.45 \\
\text { S.D. } & =0.091 \\
N & =27
\end{aligned}
$$

The Göteborg data is grouped in the high ratio end, and there are no occasions when water vapour densities greater than $11 \mathrm{gm} \mathrm{m}^{-3}$ were measured in central Göteborg during cloudless conditions observed. For the entire data set the relationship is:

$$
\begin{aligned}
R_{\mathrm{uv}} & =1.121-0.022 D \quad \text { (all data) } \\
r^{2} & =0.36 \\
\text { S.D. } & =0.085 \\
N & =44
\end{aligned}
$$

Results presented here argue that seasonal changes associated with increasing water vapour load in the troposphere could account for the difference observed between the two sites. At a coastal island, haze episodes may be more frequent than at a more inland location, especially in late summer as the warm sea surface temperature enhances evaporation into the atmosphere. Although high humidity episodes is also frequent at Göteborg, the combination of high humidity and cloudless conditions were not sampled during the field season of 1996.

Also of relevance is the daily average visibility pattern observed at Koster Island during the study period (Figure 9). These have been calculated by averaging the three-hourly observations from 06:00 to 18:00 h GMT. There is much scatter in the data, but two periods stand out as reaching low visibility values over several days. These are marked by a heavy horizontal line at the top of the chart in Figure 9. The first period, from 16 to 22 April had visibilities under $10 \mathrm{~km}$. The second period, from 8 to 31 August had visibilities under $40 \mathrm{~km}$ and three consecutive days, 17-19 August, with visibilities under 10 $\mathrm{km}$. Both of these periods were dominated by blocking anticyclones in eastern Europe, with this system prevailing on 6 days in the first period, and 12 days in the second period. 


\section{DISCUSSION AND CONCLUSION}

It was the objective of this study to examine some of the processes which could give rise to regional variability in levels of UV erythemal radiation during cloudless conditions. Towards this objective data
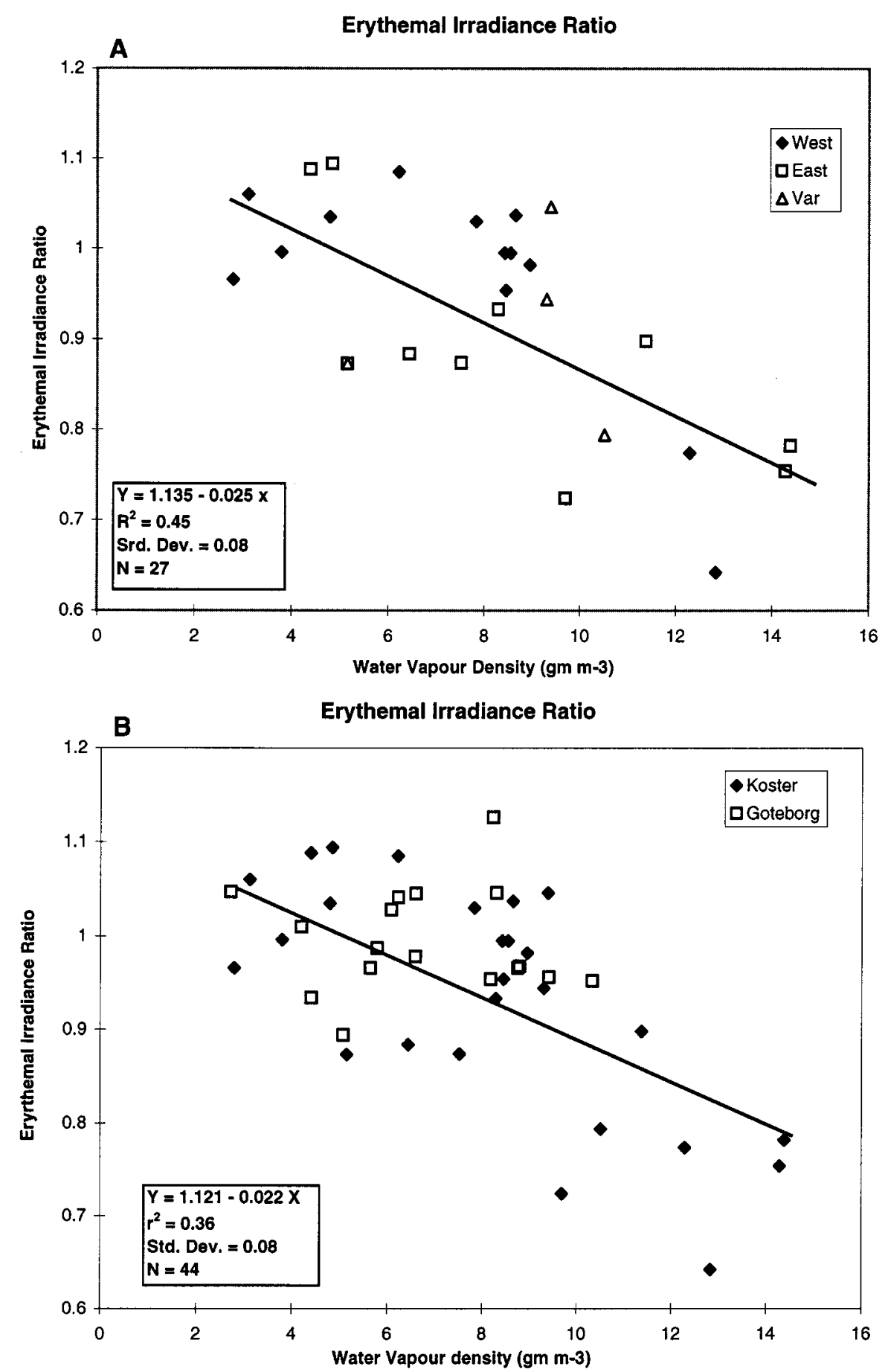

Figure 8. Erythemal irradiance ratios (measured/model) versus water vapour density $\left(\mathrm{g} \mathrm{m}^{-3}\right)$ at screen height. (a) for Koster Island. Data are also grouped according to dominant wind direction for a particular day. (b) for both Koster Island and Göteborg 
Visibility at Koster Island

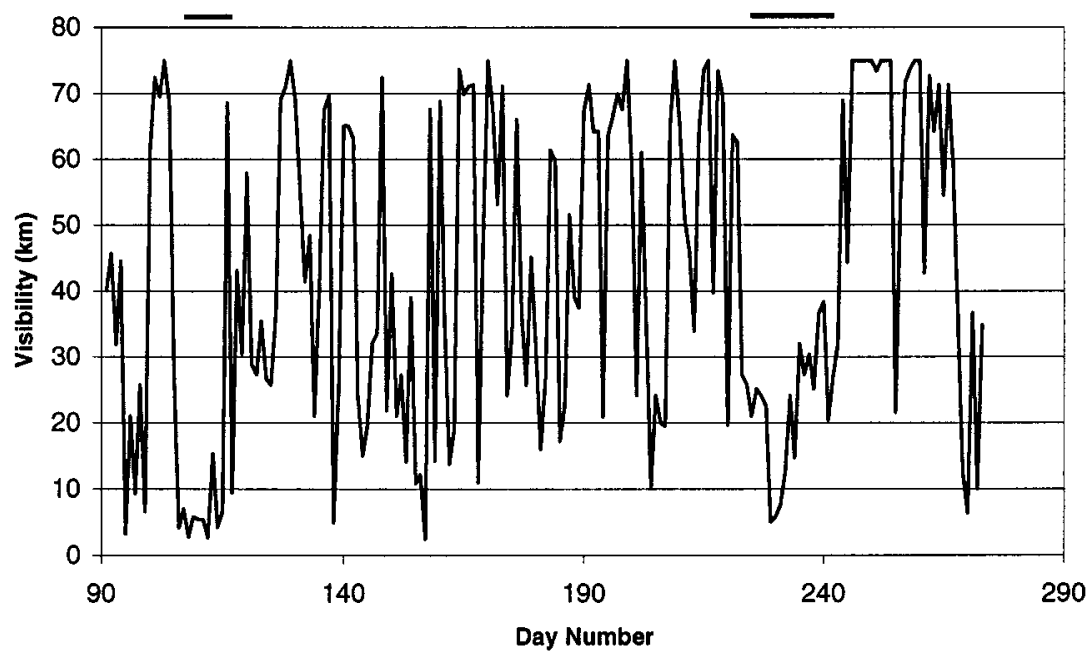

Figure 9. Daily average visibility for Koster Island during the study period

from two similar radiometers were examined during 1 April-30 September 1996 near Göteborg, Sweden. One radiometer sampled near the city centre, the second sampled at a coastal island some $143 \mathrm{~km}$ to the NNW.

The two sites exhibit considerable difference in daily erythemal irradiance even for cloudless conditions, with lower levels at Koster Island. The percentage difference ranged from a minimum of $0.9 \%$ (14 April) to $24.6 \%$ (20 August) for 4 days that were simultaneously cloudless at both sites.

Daily measured data for each site was then normalised with reference to a semi-empirical physical model. Observing the ratio of measured to model data, no trend was observed in the Göteborg ratios during the measurement programme. By contrast a distinct downward trend was observed in the ratios at the rural site, Koster Island.

Examining the variability in greater detail revealed that there was considerable uncertainty regarding which total ozone estimates to use at either site. Total ozone data from Oslo appear to give lower values than at Norrköping, which on average were 12 D.U. lower during the cloudless days measured at Koster Island. This will increase the model-predicted irradiances, and transmission ratios will be lower. Daily differences as high as 43 D.U. have been reported, which would result in model differences as high as $13 \%$. The important question to ask is how much of the variability observed in the two radiometers is due to ozone changes. Unfortunately no direct measurements of ozone were available at either site, hence it is not possible to arrive at any conclusions. In the absence of firm arguments, model data employed the average of the two daily measurements.

An examination of the broadband solar radiation data revealed decreasing ratios of solar radiation transmission $\left(R_{\mathrm{gl}}\right)$ during late summer at Koster Island. Results for Göteborg are less clear and no trend is evident. Further analysis also showed that daily variability in solar radiation transmission $\left(R_{\mathrm{gg}}\right)$ was related to the erythemal ratios $\left(R_{\mathrm{uv}}\right)$ discussed above. Finally, it was shown that erythemal ratios at both sites may be related to the surface level humidity as given by water vapour densities. This last result supports the argument that aerosols, very likely associated with coastal haze at Koster Island may at least partly explain the difference in the erythemal radiation received at the two sites.

Erythemal ratios $\left(R_{\mathrm{uv}}\right)$ for Göteborg were close to 1 when averaged over all 17 cloudless days. There is no indication of extra depletion of UV radiation due to the urban air mass in the city. It is also not possible to relate high UV radiation depletion at Koster Island to anthropogenic sources from Göteborg since no consistent pattern was found between wind direction and radiation depletion. However, the strong depletion observed in August of 1996 appear to relate to a blocking anticyclone in eastern Europe 
which was directing winds from an easterly to southerly direction into the study area. A detailed study of air masses, their sources and modification would help determine the haze conditions experienced at Koster Island.

The results presented here confirm that there are significant regional differences in the erythemal radiation received across a coastal region in Sweden. Daily variability may exist both in the total column ozone and tropospheric aerosols, so that modelling schemes which map UV irradiance across a region must take these changes into account. A measurement approach may also be used to determine regional variability. A feasible alternative may be to intercompare a set of radiometers such as the ones used here, and then deploy them in a regional pattern. The variability of erythemal irradiance may be observed, although it may be difficult to separate the contribution of total ozone from that of tropospheric aerosols.

\section{ACKNOWLEDGEMENTS}

The authors are grateful to Professor Guy Heyden of Koster Health Foundation, Göteborg University, who provided the Koster Radiation data, and to Weine Josefsson of SMHI for kindly helping us with the UV Biometer calibration. Solveig Svensson is acknowledged for drawing the map. This research is funded by the Swedish Radiation Protection Institute.

\section{REFERENCES}

Bais, A.F., Zerefos, C.S., Meleti, C., Ziomass, I.C. and Tourpali, K. 1993. 'Spectral measurements of solar UVB radiation and its relation to ozone, $\mathrm{SO}_{2}$ and clouds', J. Geophys. Res., 98, 5199-5204.

Baker, K.S., Smith, R.C. and Green, A.E.S. 1980. 'Middle ultraviolet radiation reaching the ocean surface', Photochem. Photobiol., 32, 367-374.

Blumthaler, M., Grobner, J., Huber, M. and Ambach, W. 1996. 'Measuring spectral and spatial variations of UVA and UVB irradiance', Geophys. Res. Lett., 23, 547-550.

Braslau, N. and Dave, J.V. 1973. 'Effect of aerosols on the transfer of solar energy through realistic model atmospheres', J. Appl. Meteorol., 12, 601-615.

Comission International d'Eclarage, 1987. 'A reference action spectrum for ultraviolet induced erythema in human skin', C.I.E.J., 6, $17-22$.

Dave, J.V. and Halpern, P. 1976. 'Effect of changes in ozone amount on the ultraviolet radiation received at sea level of a model atmosphere', Atmos. Environ., 1, 547-555.

Green, A.E.S., Cross, K.R. and Smith, L.A. 1980. 'Improved analytic characterization of ultraviolet skylight', Photochem. Photobiol., 31, 59-65.

Gustavsson, T., Lindqvist, S., Borne, K. and Bogren, J. 1995. 'A study of sea and land breezes in an archipelago on the west coast of Sweden', Int. J. Climatol.,15, 785-800.

Iqbal, M., 1983. An Introduction to Solar Radiation, Academic Press, New York, 390 pp.

Jokela, K., Leszczynski, K. and Visuri, R. 1993. 'Effects of Arctic ozone depletion and snow on UV exposure in Finland', Photochem. Photobiol., 58, 559-566.

Justus, C.G. and Murphey, B.B. 1994. 'Temporal trends in surface irradiance at ultraviolet wavelengths', J. Geophys. Res., 99, $1389-1394$

Kylling, A. 1995. Uvspec User's Guide, Edition 0.2 for Uvspec version 1.41, May 1995.

Liu, S.C., McKeen, S.A. and Madronich, S. 1991. 'Effect of anthropogenic aerosols on biologically active ultraviolet radiation', J. Geophys. Res., 18, 2265-2268.

Lubin, D., Ricchiazzi, P., Gautier, C. and Whritner, R.H. 1994. 'A method for mapping Antarctic surface ultraviolet radiation using multispectral satellite imagery', in Weiler, C.S. and Penhale, P.A. (eds), Ultraviolet Radiation in Antarctica: Measurements and Biological Effects, Antarctic Research series, Vol. 62, American Geophysical Union, Washington D.C., pp. 53-81.

Nack, M.I. and Green, A.E.S. 1974. 'Influence of clouds, haze and smog on the middle ultraviolet reaching the ground', Appl. Optics, 13, 2405-2415.

Nemeth, P., Toth, Z. and Nagy, Z. 1996. 'Effect of weather conditions on UV-B radiation reaching the earth's surface', Photochem. Photobiol., 32, 177-181.

Nunez, M. and Kalma, J.D. 1996. 'Satellite mapping of the surface radiation budget', Adv. Bioclimatol., 4, $63-124$.

Nunez, M., Michael, K., Turner, D., Wall, M. and Nilsson, C. 1997. 'A satellite-based climatology of UV-B irradiance for Antarctic coastal regions', Int. J. Climatol., 17, 1029-1054.

Scotto, J., Cotton, G., Urbach, F., Berger, D. and Feras, T. 1988. 'Biologically effective ultraviolet radiation: surface measurements in the United States, 1974-1985', Science, 239, 762.

Seckmeyer, G. and McKenzie, R.L. 1992. 'Increased ultraviolet radiation in New Zealand $\left(45^{\circ} \mathrm{S}\right)$ relative to Germany ( $\left.48^{\circ} \mathrm{N}\right)$ ', Nature, 359, 135-137.

Solar Light, 1991. User's Manual for UV-B Biometer Model 501, $22 \mathrm{pp}$.

Zerefos, C.S., Meleti, C., Bais, A.F. and Lambros, A. 1995. 'The recent UVB variability over southeastern Europe', Photochem. Photobiol., 31, 15-19 